\title{
MARKOV SWITCHING INTERCEPT VECTOR AUTOREGRESSIVE MODEL (MSI(2)-VAR(2)) OF NIGERIA INFLATION RATE AND CRUDE OIL PRICE (USING VIEWS 11)
}

\author{
Wiri Leneenadogo ${ }^{1}$, Sibeate Pius U. $^{2}$ and Isaac Didi Essi ${ }^{3}$ \\ ${ }^{1}$ Rivers State Ministry of Education, Port Harcourt Nigeria. \\ ${ }^{2}$ Department of PRS (Statistics \& EMIS Unit), Rivers State Ministry of Education, Port \\ Harcourt, Nigeria. \\ ${ }^{3}$ Department of Mathematics Rivers State University, Port Harcourt. \\ Email:weesta12@gmail.com
}

Cite this article:

Wiri L., Sibeate P.U., Isaac D.E. (2021), Markov Switching Intercept Vector Autoregressive Model (MSI(2)-VAR(2)) of Nigeria Inflation Rate and Crude Oil Price (Using Views 11). African Journal of Mathematics and Statistics Studies 4(2), 88-100. DOI: 10.52589/AJMSSVY1OOCXZ.

\section{Manuscript History}

Received: 25 June 2021

Accepted: 21 July 2021

Published: 9 Aug 2021

Copyright $\odot 2020$ The Author(s). This is an Open Access article distributed under the terms of Creative Commons AttributionNonCommercial-NoDerivatives 4.0 International (CC BY-NC-ND 4.0), which permits anyone to share, use, reproduce and redistribute in any medium, provided the original author and source are credited.
ABSTRACT: To model inflation rate and crude oil prices, we used Markov Switching intercept heteroscedasticity Vector Autoregressive models. The data for this analysis was gathered from the Central Bank of Nigeria Statistical Bulletin monthly. The upward and downward movement in the series revealed by the time plot suggests that the series exhibit a regime-switching pattern: the period of expansion and contraction. The variable was stationary at first differences, the Augmented Dickey-Fuller test was used to screen for stationarity. The information criteria were used to test the number of regime and regime two were selected. Eight models were estimated for the MSI-VAR model. The best model was chosen based on the criterion of least information criterion, Markov-switching intercept heteroscedasticity - Vector Autoregressive model (MSIH(2)VAR(2)) with AIC (8.596641) and SC (8.973119). The model was used to predict the series' values over a one-year cycle (12 months).

KEYWORD: Inflation Rate, Crude Oil Prices, Markov Switching Intercept Heteroscedasticity, VAR, Forecast 


\section{INTRODUCTION}

For a long time, the price of crude oil and the rate of inflation in Nigeria have been inextricably linked. As the price of crude oil rises, the rate of inflation rises with it. Oil is a major source of income in Nigeria's economy, and it is used in vital activities such as fuelling, transportation, and home heating, among others. ( http://www.cenbank.org ).There is a progression of rises and falling (expansions and contractions) between the two series, which fluctuate around a higher and lower stage. It would be unreasonable to expect a single linear or multivariate model to capture these distinct behaviours for such data.

The Hamilton (1989) introduces the Markov switching model, also known as the regimeswitching model, is one of the most commonly used nonlinear time series models. Multiple structural equations were used in this model to describe time series behaviour in various regimes (expansion and contractions, etc). This model can capture more complex dynamic patterns by allowing switching between each regime. The switching mechanism of the Markov Switching Model is regulated by observable and unobservable state variables that follow a firstorder Markov chain.

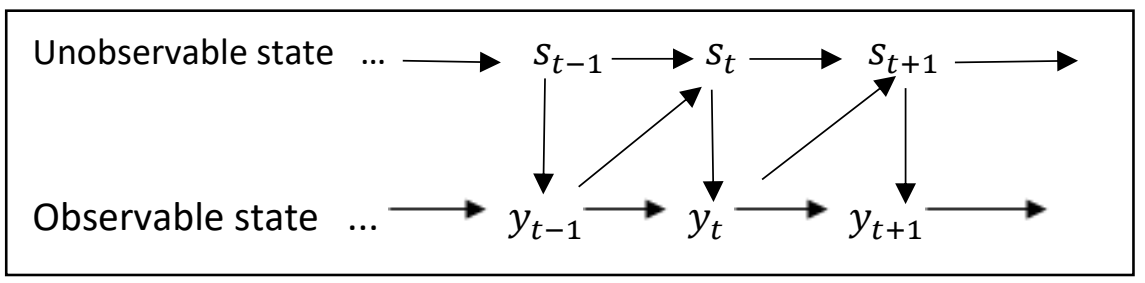

Figure 1.1: Switching Process

Unobservable state $s_{t}$, Observable state $y_{t}$; Monbet \& Ailliot (2017).

The Markovian property, in particular, allows the current value of the state variable to be influenced by its recent past values. As a result, a structure may be dominant for a random period before being replaced by another structure when switching occurs. The regimeswitching model differs from Quaudt (1983) random switching model, in which the switching events are time-independent. As a result, the Markov switching model is well suited in modelling nonlinear time series that explain complex patterns over time (expansion and contraction). The concept of this study is based on MS-VAR modelling of crude oil prices and inflation rate in Nigeria.

\section{LITERATURE REVIEW}

Krolzig (1998) replicate Hamilton (1989) model of the US business cycle, The model proposes by Hamilton (1989) for the US business cycle is MS(2)-AR(4). Krolzig extend the idea of Hamilton of a univariate non-linear model to multivariate models using MS-VAR for estimating business cycles of Six OECD countries of four content in the ox file (WBC.ox) Matthieu and Tomasz (2016) their examined difference type of regime-switching models based 
on the series of income and money data. The technique aborted is the MS-VAR process with restriction for Grange causality.

Krolzig \& Juan (2000) examined the business cycles in Europe using a different method to analyse the series. These methods are the approach proposed in Burnitched (1946) the approach proposed by Hamilton (1989) the two approaches are compared using business cycles in European economies. The countries are Germany and France. The record a similar to expansion and recession, Spain and Germany have a similar expansion duration but the duration of contraction in Spain is almost half the value of Germany and Frances. The UK and Australia seen to have similar expansion duration wish are half the record for Frances and Germany. The MS-VAR models performed better than all other models.

Gabriele et al (2014) used VECM to study the relationship between the exchange rate, money supply, prices of import and prices of export. The result showed that exchange rate shock is significant after the fluctuation of import prices. Durka and Pastorekov (2012) applied a vector autoregressive model to modelled the relationship between economist variable. The study reveals that the exchange rate is Granger cause the economy, oil revenues, government expenditure.

Handoienu(2008) Examined the relationship between exchange rate and inflation rate used a using vector autoregressive model to determine the impact of the exchange rate on the inflation rate of Romania. The result indicates that a $1 \%$ change in the exchange rate causes a modification of $0.36 \%$ point to producer prices index-based inflation rate.

\section{METHODOLOGY}

\section{Time Plot}

When dealing with time-series data, the first step in the study is to create time plots of the series to analyse the properties of the series. The graph of inflation and crude oil prices are plotted against time to give us the overall movement of the original data over time. This graph also shows the researcher: Trend, seasonal fluctuation, Constant variances, and the duration of expansion and contraction.

\section{Markov Switching Model}

Markov switching models are time series models in which variables can switch from one state to the next in a defined number of regimes. As part of the model, a stochastic mechanism that allows variables to switch between regimes according to an unobserved Markov chain was used to produce the regime shifts in the past and present. Threshold models and Markovswitching models are the two types of regime-switching models. The primary difference between these approaches is how the state process is modelled. Threshold models, introduced by Tong (1983), assume that regime shifts are triggered by the level of observed variables about an unobserved threshold. Markov-switching models, introduced by Hamilton (1989), assume that the regime shifts according to a Markov chain.

Markov-switching models also assume that $S_{t}$ is the unobserved variable and $y_{t}$ an observed variable. In contrast to threshold models, however, $S_{t}$ is assumed to follow a particular 
stochastic process, namely an $N$ state Markov chain. The development of Markov chains is described by their transition probabilities, given by:

$\operatorname{Pr}\left(S_{t}=i / S_{t-1}=j, S_{t-2}=q \ldots \ldots ..\right)=\operatorname{Pr}\left(S_{t}=i / S_{t-1}=j\right)=\operatorname{Prij}$

Where conditional on a value of $j$, we assume $\sum_{i=1}^{n} P r_{i j}=1$. That is, the process specifies a complete probability distribution for $S_{t}$. In general, the Markov process allows regimes to be a switch from one state to another and for regimes to switch, more than once restrictions can be placed on $\operatorname{Pr}_{i j}$ to restrict the order of regime shifts. Hamilton (1990)

\section{Markov Switching Vector Autoregressive Model}

The MS-VAR models are used to predict VAR models when the regime shifts from an observable state to an unobservable state. This model describes a non-linear data generation process as piecewise linear by constraining the process to be linear in each regime. Markovswitching vector autoregressive can be considered as generalizations of the basic finite order VAR model of order $\mathrm{p}$. If the process is subject to shifts in the regime, the stable vector autoregressive model with its time-invariant parameters might be inappropriate. The idea behind this class of models is that the parameters of the underlying data generating process of the observed variables $y_{i}$ depend upon the unobservable regime variable $S_{t}$ which represents the probability of being in a different state at a different time follow a first-order Markov chain. The description of the data-generating process is not complete by the observational equations. A model for the regime generating process has to be formulated which then allows the evolution of regimes from the data. Hamilton (1989). The general characteristic of the Markov switching model is that the unobservable realization of the regime $S_{t} \in(1,2, \ldots \ldots \ldots N)$ is governed by

(i) discrete-time,

(ii) discrete-state,

which is defined by the transition probabilities

$P_{i j}=\operatorname{Pr}\left(S_{t-j}=j / S_{t}=\mathrm{i}\right) . \sum_{j=1}^{N} P_{i j}=1, \forall_{i j} \in\{1,2, \ldots \ldots \ldots . N\}$

(iii) In general, $S_{t}$ follows an irreducible ergodic $\mathrm{N}$ state Markov process with the transition matrix

$$
\mathrm{P}=\left[\begin{array}{ccccc}
p_{11} & p_{12} & \cdot & \cdot & p_{1 N} \\
p_{21} & p_{22} & \cdot & \cdot & p_{2 N} \\
\cdot & \cdot & \cdot & \cdot & \cdot \\
\cdot & \cdot & \cdot & \cdot & \cdot \\
p_{i 1} & p_{i 2} & \cdot & \cdot & p_{i N}
\end{array}\right]
$$

$P_{i N}=1-p_{11}----------p_{i N-1}$

for $i=1 \ldots \ldots \ldots \ldots \ldots \ldots N$ 
The assumptions of ergodicity and irreducibility are important for the theoretical properties of Markov switching vector autoregressive models. A comprehensive discussion of the theory of Markov chains with application to Markov-switching models is given by Hamilton (1989).

\section{Markov Switching Vector Autoregressive Model (MS(N)-VAR(P))}

In the general specification of an $\operatorname{MS}(m)-\operatorname{VAR}(\mathrm{p})$ model, all parameters of the autoregressive are conditioned on the state $\boldsymbol{S}_{\boldsymbol{t}}$ of the Markov chain such that each regime (m)-VAR(p) parameters as following as regime process.

Generally

$$
\begin{aligned}
& Y_{t}=v_{s_{t}}+\sum_{i=1}^{p} b_{i, s_{t}} Y_{t-i}+\boldsymbol{\sigma}_{\boldsymbol{s}_{\boldsymbol{t}}}^{\mathbf{1} \mathbf{2}} \boldsymbol{\varepsilon}_{\boldsymbol{i}} \\
& Y_{t}=\left\{\begin{array}{c}
v_{1}+b_{1,1} y_{t-1}+\ldots \ldots \ldots \ldots+b_{p, 1} y_{t-p}+\sigma_{1}^{1 / 2} \varepsilon_{i} \text { if } s_{t}=1 \\
\cdot \\
\cdot \\
v_{m}+b_{1, m} y_{t-1}+\cdots \ldots \ldots \ldots+b_{p}, m y_{t-p}+\sigma_{m}^{1 / 2} \varepsilon_{i} \text { if } s_{t}=\mathrm{m}
\end{array}\right.
\end{aligned}
$$

Where $Y_{t}=\left(\begin{array}{c}Y_{1} \\ \cdot \\ \cdot \\ Y_{p}\end{array}\right), b_{i}=\left(\begin{array}{ccccc}b_{11} & \cdot & \cdot & \cdot & b_{1 p} \\ \cdot & \cdot & \cdot & \cdot & \cdot \\ \cdot & \cdot & \cdot & \cdot & \cdot \\ b_{p 1} & \cdot & \cdot & \cdot & b_{p p}\end{array}\right), Y_{t-i}=\left(\begin{array}{c}Y_{t-1} \\ \cdot \\ \cdot \\ Y_{t-p}\end{array}\right), s_{t}=\left\{\begin{array}{c}1 \text { if } s_{t}=1 \\ \cdot \\ m \text { if } s_{t}=m\end{array}\right.$

$v_{s_{t}}=\left(\begin{array}{c}v_{1, s_{t}} \\ \cdot \\ \cdot \\ v_{1, s_{t}}\end{array}\right), \sigma_{s_{t}}^{1 / 2}$ is the choleski decomposition of the return shock covariance

$$
\varepsilon_{i} \sim N\left(0, \boldsymbol{\sigma}_{s_{t}}^{1 / 2}\right)
$$

For analytical applications, however, it may be more useful to use a model in which only certain parameters are conditioned on the state of the Markov chain and the rest are regime invariant. When the autoregressive parameters, the mean and intercepts, are regime dependent, and the error term is heteroscedasticity or homoscedasticity, special MSVAR models may be implemented.

The MS(m)-VAR(p) models also allow for a variety of specifications. Krolzig (1998)

Established a common notation for expressing the models in which various parameters are subject to shifts in regime with the varying and invariant state.

Note: $\mu=$ mean, $v=$ intercept term, $\sigma=$ Variance and $b_{i}=$ matrix of autoregressive parameter

An overview of Markov switching vector autoregressive models is given in table 1.3. In many situations $\operatorname{MSI}(\mathrm{m})-\mathrm{VAR}(\mathrm{p})$ and $\operatorname{MSM}^{-}(\mathrm{m})-\mathrm{VAR}(\mathrm{p})$ models will be sufficient, a regimedependent covariance structure of the process might be considered as an additional feature. 


\section{Markov Switching Intercept Vector Autoregressive Model (MSI(M)-VAR(P))}

Occasionally, it may be more plausible to assume that the mean smoothly approaches a new level after the transition from one state to another. In such a situation the following model with a regime-dependent intercept term $\left(\boldsymbol{v}_{\boldsymbol{s}_{t}}\right)$ may be used

$$
Y_{t}=v_{s_{t}}+b_{1}, S_{t} y_{t-1}+\ldots \ldots \ldots \ldots . .+b_{p}, S_{t} y_{t-p}+\sigma_{S_{t}}^{1 / 2} \varepsilon_{i}
$$

Where

$\varepsilon_{i} \sim \operatorname{NID}\left(0, \sigma_{S_{t}}\right)$, are shift function describing the dependence of the parameter $\epsilon$,

The mean adjusted form and the intercept of an $\operatorname{MSI}(\mathrm{m})-\mathrm{VAR}(\mathrm{p})$ model are not equivalent. In Krolzig (1998) it is shown that these forms imply different dynamic adjustments of the observed variables after a regime change. While a permanent regime shift in the mean $\boldsymbol{\varepsilon}\left(\mathrm{S}_{\mathrm{t}-1}\right)$ causes an immediate jump of the observed time series vector onto its new level, the dynamic response to all regime shift in the intercept term $\boldsymbol{v}_{\boldsymbol{s}_{\boldsymbol{t}}}$ is identical to an equivalent shock in the white noise series $\boldsymbol{\varepsilon}_{\boldsymbol{i}}$.

Table 3.1: Models Specification of (MSI(M)-VAR(P))

\begin{tabular}{llll}
\hline Parameter/Model & \multicolumn{1}{c}{ I } & \multicolumn{1}{c}{$\boldsymbol{B}_{\boldsymbol{i}}$} & \multicolumn{1}{c}{$\boldsymbol{\sigma}$} \\
\hline MSI-VAR & Varying & Invariant & Invariant \\
MSIH-VAR & Varying & Invariant & Varying \\
MSIA-VAR & Varying & Varying & invariant \\
MSIAH-VAR & Varying & Varying & Varying \\
Linear-VAR & Invariant & Invariant & Invariant \\
MSH-VAR & Invariant & Invariant & Varying \\
MSA-VAR & Invariant & Varying & Invariant \\
MSAH-VAR & Invariant & Varying & Varying \\
\hline
\end{tabular}

Note:, $I=$ intercept term, $\sigma=$ Variance and $b_{i}=$ matrix of autoregressive parameter

We define the general Markov switching models, the regime-dependent parameter as follows, to create a unique notation for each model: Clement \& Krolzig (2002)

MSI-VAR Markov-switching intercept-VAR

MSIA-VAR Markov-switching intercept Autoregressive-VAR

MSIH-VAR Markov-switching intercept heteroscedasticity -VAR

MSIAH-VAR Markov-switching intercept Autoregressive heteroscedasticity-VAR

LINEAR-VAR Linear - VAR

MSH-VAR Markov-switching heteroscedasticity -VAR

MSA-VAR Markov-switching Autoregressive - VAR

MSAH-VAR Markov-switching Autoregressive heteroscedasticity - VAR 


\section{Testing for the Number of Regimes}

Who?Propose that in practices, It's advisable to used information criteria to test for the number of a regime that using the likelihood ratio test. Base on the above assumption by Guidolin (2012) the following information criteria are used to estimate the number of regime between the series. The commonly used information criteria are:

(i) Akaike information criterion (AIC),

(ii) Hannah-Quinn information criterion (HQ)

(iii) Schwarz information criterion (SIC).

$$
\begin{aligned}
& >\mathrm{AIC}=\ln \left|\Sigma_{r}\right|+\frac{2}{T} \mathrm{MK}^{2} \\
& >\mathrm{HQ}=\ln \left|\Sigma_{r}\right|+\frac{2 \operatorname{In} T}{T} \mathrm{M} K^{2} \\
& >\mathrm{SC}=\ln \left|\Sigma_{r}\right|+\frac{\operatorname{In} T}{T} \mathrm{M} K^{2}
\end{aligned}
$$

$\mathrm{T}$ is the number of observations (after accounting for lags)

$\mathrm{M}$ is the number of parameters estimated in each equation of the unrestricted system, including the constant. $\ln \left|\Sigma_{r}\right|$ is the natural log of the determinant of the covariance matrix of residuals of the restricted system. In each case, $\mathrm{M} K^{2}$ is the number of VAR parameter in a model with order M.

\section{RESULT}

\section{Time Plot of Crude Oil Prices and Inflation Rate}

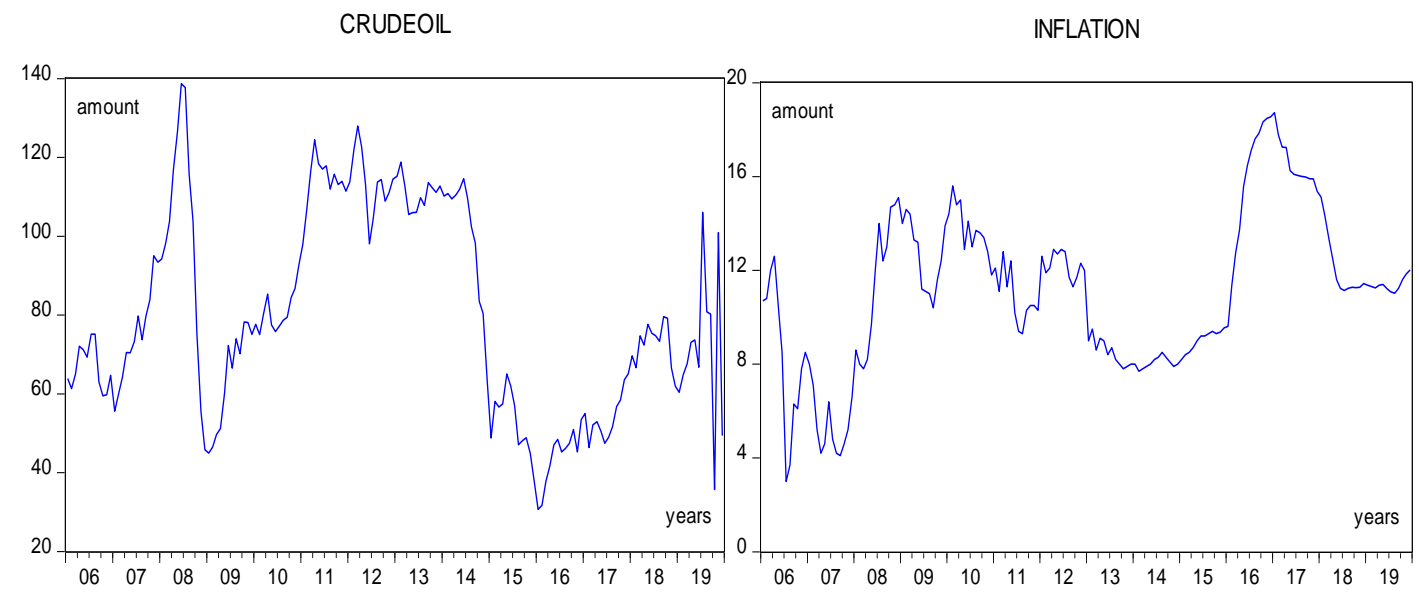

A closer analysis of the time plots showed upward and downward movement in both series, suggesting that the series have a regime-switching pattern (a cycle of expansion and contraction in their movement), indicating a period of two regimes in the variable under study. The 
variables involved in this study were tested for stationarity using The Augmented DickeyFuller (ADF).at first differences, constant, linear trend and all the variables, the result showed the presence of unit root.

Table 4.1: Testing the Number of Regimes

Since $S_{t}=1,2,3 \ldots \ldots . . N, N \geq 2$

\begin{tabular}{|l|l|l|}
\hline Regime & AIC & SC \\
\hline 2 & 9.441754 & 9.76176 \\
\hline 3 & 9.67859 & 10.2345 \\
\hline 4 & 10.2893 & 10.93452 \\
\hline
\end{tabular}

The best regime is selected base on minimum information criteria. The commonly used information criteria are the Akaike information criterion and Schwarz information criterion (SIC). Regime 2 has the minimum information criteria with an AIC of 9.441754 and SC of 9.76176.

Models Estimation Markov Switching Intercept Vector Autoregressive of order 2 (MSI(2)-Var(2)) With (AIC), (SC), Log-Likelihood

\begin{tabular}{lllll}
\hline S/N & \multicolumn{4}{c}{ Akaike info } \\
& Estimated Models & \multicolumn{1}{c}{ Criterion } & Schwarz criterion & Log-likelihood \\
\hline 1 & MSI(2)-VAR(2) & 9.414122 & 9.734128 & -729.7498 \\
$\mathbf{2}$ & MSIH(2)-VAR(2) & $\mathbf{8 . 5 9 6 6 4 1}$ & $\mathbf{8 . 9 7 3 1 1 9}$ & $\mathbf{- 6 8 9 . 2 2 9}$ \\
3 & MSIA(2)-VAR(2) & 9.117466 & 9.58806 & -727.1909 \\
4 & MSIAH(2)-VAR(2) & 8.841102 & 9.36817 & -701.3910 \\
5 & LINEAR-VAR(2) & 9.307689 & 9.60887 & -751.8844 \\
6 & MSH(2)-VAR(2) & 9.00181 & 9.35947 & -723.6501 \\
7 & MSA(2)-VAR(2) & 9.117511 & 9.56289 & -728.1950 \\
8 & MSAH(2)-VAR(2) & 9.08812 & 9.59336 & -722.5224 \\
\hline
\end{tabular}

Source: Researchers computation with Eviews 11

\section{Estimation of Non- Linear Multivariate Models with Schwarz Criterion, Log-Likelihood} and Akaike Information Criterion.

Eight models for Markov switching intercept vector autoregressive model (MSI(2)-VAR(2)). The Markov switching vector autoregressive model allows for a great variety of specifications such as Markov-switching intercept term, Markov-switching autoregressive and Markovswitching heteroscedasticity. All variables were stationary at lag 1 . The best model was selected base on minimise information criterion. The MSIH(2)-VAR(2) is the best model with the following information criterion AIC (8.596641), SC (8.973119) and the largest loglikelihood (-689.229). Chris-Book(2008) 


\section{Model Representation of MSIH(2)-VAR(2) of Crude Oil Price and Inflation Rate}

At regime one (1) expansion the model can be rewrite as follow:

$$
\begin{aligned}
& \left(\begin{array}{c}
\text { inf }_{t} \\
\dot{c^{\prime}} \\
\text { op }_{t}
\end{array}\right)=\left(\begin{array}{cc}
0.049461 & ? \\
-0.798871 & ?
\end{array}\right)+\left(\begin{array}{cc}
0.32264 & -0.194423 \\
-0.000239 & 0.28687
\end{array}\right)\left(\begin{array}{c}
\text { inf }_{t-1} \\
\vdots \\
\operatorname{cop}_{t-1}
\end{array}\right)+ \\
& \left(\begin{array}{cc}
0.110491 & -0.085539 \\
0.02331 & 0.08196
\end{array}\right)\left(\begin{array}{c}
\text { inf } \\
\vdots \\
\operatorname{cop}_{t-2}
\end{array}\right)+\left(\begin{array}{c}
0.1319 \\
5.33
\end{array}\right)\left(\begin{array}{c}
\varepsilon_{\text {expan }}^{\text {inf }} \\
\text { cop } \\
\varepsilon_{\text {expan }}
\end{array}\right) \\
& \varepsilon_{\text {expan }} \sim\left(0, \quad\left(\begin{array}{cc}
0.01741 & -0.035029 \\
-0.035029 & 28.40913
\end{array}\right)\right)
\end{aligned}
$$

At regime two (2) contraction the model can be rewrite as follow:

$$
\begin{aligned}
& \left(\begin{array}{c}
\text { inf }_{t} \\
\dot{c^{\prime}} \\
\operatorname{cop}_{t}
\end{array}\right)=\left(\begin{array}{c}
-0.033720 \\
0.426786
\end{array}\right)+\left(\begin{array}{cc}
0.32264 & -0.194423 \\
-0.000239 & 0.28687
\end{array}\right)\left(\begin{array}{c}
\text { inf } \\
\vdots \\
\vdots \\
\operatorname{cop}_{t-1}
\end{array}\right)+ \\
& \left(\begin{array}{cc}
0.110491 & -0.085539 \\
0.02331 & 0.08196
\end{array}\right)\left(\begin{array}{c}
\text { inf } f_{t-2} \\
\vdots \\
\operatorname{cop}_{t-2}
\end{array}\right)+\left(\begin{array}{l}
1.246 \\
6.489
\end{array}\right)\left(\begin{array}{c}
\varepsilon_{\text {expan }}^{\text {inf }} \\
\varepsilon_{\text {expan }}^{\text {cop }}
\end{array}\right) \\
& \varepsilon_{\text {cont }} \sim\left(0, \quad\left(\begin{array}{cc}
1.55312 & -0.383186 \\
-0.383186 & 42.11081
\end{array}\right)\right)
\end{aligned}
$$

The Transition Probability of MSIH(2)-VAR(2) from Regime 1 to Regime 2 is Presented below

\begin{tabular}{|l|c|c|c|c|c|c|c|c|}
\hline \multirow{2}{*}{ Variables } & \multicolumn{4}{|l|}{ Transition Probability } & \multicolumn{4}{l|}{ Expected Duration } \\
\cline { 2 - 9 } & $\mathbf{P}_{\mathbf{1 1}}$ & $\mathbf{P}_{\mathbf{1 2}}$ & $\mathbf{P}_{\mathbf{2 1}}$ & $\mathbf{P}_{\mathbf{2 2}}$ & $\mathbf{E}_{\mathbf{1 1}}$ & $\mathbf{E}_{\mathbf{1 2}}$ & $\mathbf{E}_{\mathbf{2 1}}$ & $\mathbf{E}_{\mathbf{2 2}}$ \\
\hline $\begin{array}{l}\text { MSIH(2)- } \\
\text { VAR(2) }\end{array}$ & 0.932846 & 0.067154 & 0.030513 & 0.96487 & 14.89 & 1.071 & 1.03 & 32.773 \\
\hline
\end{tabular}

\section{The Transition Matrix Crude Oil Prices}

$P_{i j}=\left[\begin{array}{ll}P_{11} & P_{12} \\ P_{21} & P_{22}\end{array}\right]=\left[\begin{array}{cc}0.932846 & 0.0671554 \\ 0.0 .030513 & 0.96487\end{array}\right]$

Where $P_{11}+P_{12}=1, P_{21}+P_{22}=1$

The probability of transitioning to expansion in the next period given that the current state is in expansion is 0.932846 , probability of transitioning to a contraction in the next period given that the current state is in expansion is 0.0671554 . The probability of transitioning to expansion in the next period given that the current state is in contraction 0.030513 . The probability of 
transitioning to a contraction in the next period given that the current state is in contraction 0.96487 .

\section{Expected Duration}

The expected time spent in each state is called the expected duration. If $D_{1}$ is the expected duration spend in state 1 , The closer $P_{i j}$ is to 1 the higher is the expected duration of state 1 .

\section{Markov Switching Filtered Regime Probabilities}

$P(S(t)=1)$
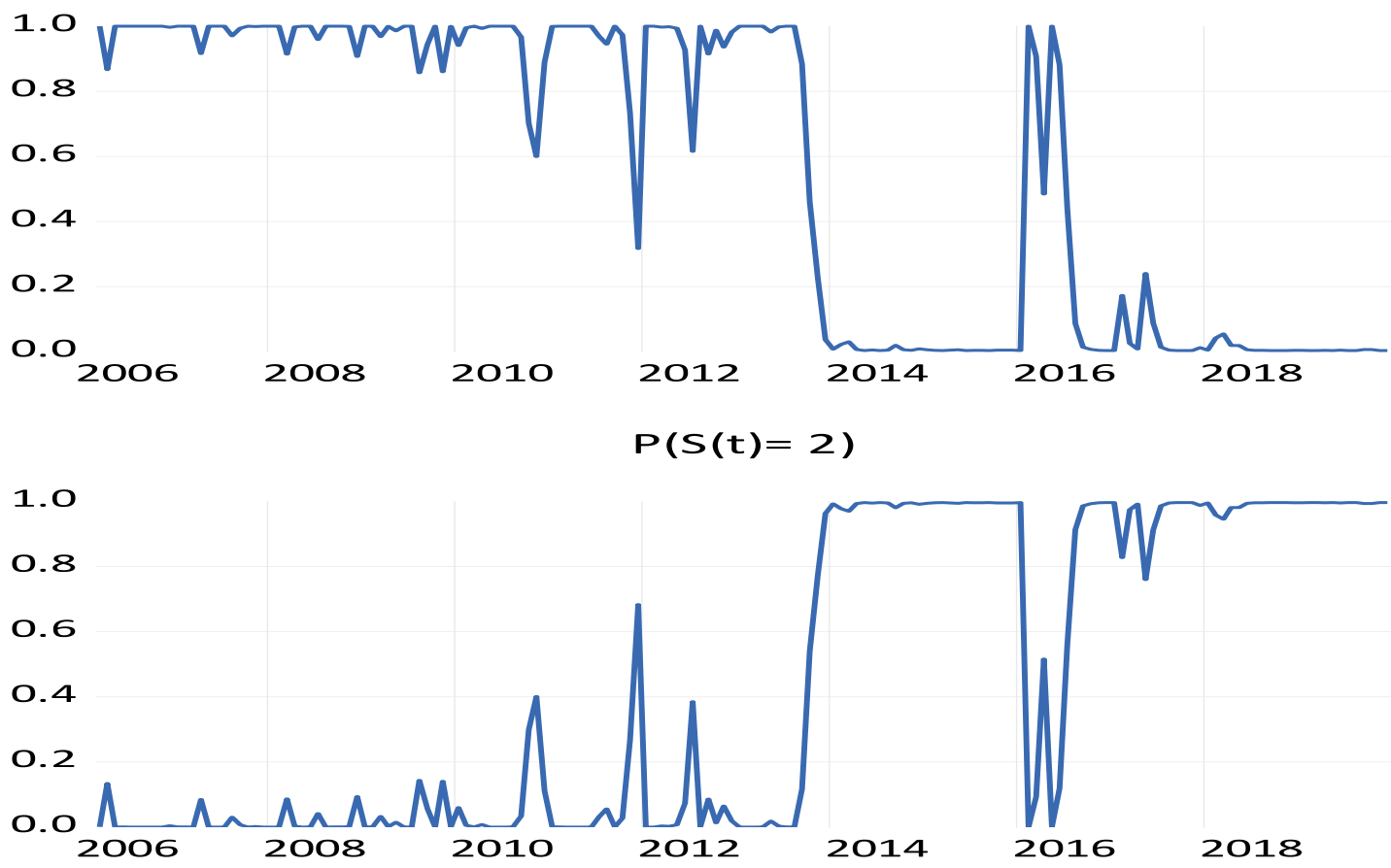

Figure 4.13: $\quad$ Markov Switching Filtered Regime Probabilities of $(\operatorname{Ms}(2) \operatorname{Var}(2))$

The smoothed probabilities and filtered probability are showed in figure 4.18 which provide inference on $s_{t}$ conditional on all available sample information. In regime one $\operatorname{pr}\left(s_{t}=1\right)$, we find out that the smoothing process is high and remain high till 2014 and fluctuating up and down at the end of the regime. regime two $\operatorname{pr}\left(s_{t}=2\right)$, contraction smoothing process is in opposite direction similar to regime one smoothing start from down and remained down till 2013 and fluctuate up and down till the end. These indicate unstable prices of oil in international which may lead to the financial crisis. The filtered probability has a similar pattern with the smoothed probability. 
Foresting the Value of Crude Oil Prices and Inflation Rate from January 2020-June 2020

At regime one (1) expansion the forest model can rewrite as follow

Where $t=($ January 2020)

$$
\begin{aligned}
& \left(\begin{array}{c}
\text { inf }_{t} \\
\cdot \\
\operatorname{cop}_{t}
\end{array}\right)=\left(\begin{array}{c}
0.049461 \\
-0.798871
\end{array}\right)+\left(\begin{array}{cc}
0.32264 & -0.194423 \\
-0.000239 & 0.28687
\end{array}\right)\left(\begin{array}{c}
\text { inf } f_{t-1} \\
\vdots \\
\operatorname{cop}_{t-1}
\end{array}\right)+ \\
& \left(\begin{array}{cc}
0.110491 & -0.085539 \\
0.02331 & 0.08196
\end{array}\right)\left(\begin{array}{c}
\text { inf } \\
\vdots \\
\operatorname{cop}_{t-2}
\end{array}\right)(5.24)
\end{aligned}
$$

At regime two (2) contraction the model can be rewrite as follow

$$
\begin{aligned}
& \left(\begin{array}{c}
\text { inf }_{t} \\
\dot{c^{\prime}} \\
\operatorname{cop}_{t}
\end{array}\right)=\left(\begin{array}{c}
-0.033720 \\
0.426786
\end{array}\right)+\left(\begin{array}{cc}
0.32264 & -0.194423 \\
-0.000239 & 0.28687
\end{array}\right)\left(\begin{array}{c}
\text { inf } \\
\vdots \\
\vdots \\
\operatorname{cop}_{t-1}
\end{array}\right)+ \\
& \left(\begin{array}{cc}
0.110491 & -0.085539 \\
0.02331 & 0.08196
\end{array}\right)\left(\begin{array}{c}
\text { inf } \\
\vdots \\
\operatorname{cop}_{t-2}
\end{array}\right)(5.25)
\end{aligned}
$$

Where $t=t+11($ December 2020)

At regime one (1) expansion the forest model can rewrite as follow

$$
\begin{aligned}
& \left(\begin{array}{c}
\text { inf }_{t+11} \\
\cdot \\
\text { cop }_{t+11}
\end{array}\right)=\left(\begin{array}{c}
0.049461 \\
-0.798871
\end{array}\right)+\left(\begin{array}{cc}
0.32264 & -0.194423 \\
-0.000239 & 0.28687
\end{array}\right)\left(\begin{array}{c}
\text { inf } f_{t-10} \\
\vdots \\
c o p_{t-10}
\end{array}\right)+ \\
& \left(\begin{array}{cc}
0.110491 & -0.085539 \\
0.02331 & 0.08196
\end{array}\right)\left(\begin{array}{c}
\text { inf }_{t-9} \\
\vdots \\
\text { cop }_{t-9}
\end{array}\right)(5.26)
\end{aligned}
$$

At regime two (2) contraction the model can be rewrite as follow

$$
\begin{aligned}
& \left(\begin{array}{c}
\text { inf }_{t+11} \\
\vdots \\
\operatorname{cop}_{t+11}
\end{array}\right)=\left(\begin{array}{c}
-0.033720 \\
0.426786
\end{array}\right)+\left(\begin{array}{cc}
0.32264 & -0.194423 \\
-0.000239 & 0.28687
\end{array}\right)\left(\begin{array}{c}
\text { inf }_{t-10} \\
\vdots \\
\operatorname{cop}_{t-10}
\end{array}\right)+ \\
& \left(\begin{array}{cc}
0.110491 & -0.085539 \\
0.02331 & 0.08196
\end{array}\right)\left(\begin{array}{c}
\text { inf }_{t-9} \\
\vdots \\
\operatorname{cop}_{t-9}
\end{array}\right)
\end{aligned}
$$


Table 4.13: Forecast Value of Inflation Rate and Crude Oil Prices in Nigeria

\begin{tabular}{|c|c|c|c|c|c|c|}
\hline \multirow[t]{2}{*}{ Month } & \multicolumn{3}{|c|}{$\begin{array}{l}\text { Forecast Value of Inflation Rate } \\
\text { for } 2020 \text { January }-2020 \text { December }\end{array}$} & \multicolumn{3}{|c|}{$\begin{array}{l}\text { Forecast Value of Crude Oil Prices } \\
\text { for } 2020 \text { January } \mathbf{- 2 0 2 0} \text { December }\end{array}$} \\
\hline & Regime1 & Regime2 & Average & Regime 1 & Regime 2 & Average \\
\hline January & 11.99969 & 11.9165 & 11.958 & 58.476 & 59.70189 & 59.0889 \\
\hline February & 12.12269 & 11.69151 & 11.90710 & 57.544 & 60.36689 & 58.9665 \\
\hline March & 12.88959 & 11.3974 & 12.14349 & 56.45244 & 61.07625 & 58.76234 \\
\hline April & 13.93943 & 11.0492 & 12.49431 & 55.26 & 61.80165 & 58.530825 \\
\hline May & 15.1844 & 10.6692 & 12.9268 & 54.0304 & 62.53495 & 58.282 \\
\hline June & 16.53701 & 10.2699 & 13.40345 & 52.783 & 63.27185 & 58.027425 \\
\hline July & 17.9531 & 9.8594 & 13.90625 & 51.548 & 64.0104 & 57.826 \\
\hline August & 19.56901 & 9.4426 & 14.5058 & 50.29594 & 64.74897 & 57.522455 \\
\hline September & 20.81669 & 9.0222 & 14.919 & 49.03994 & 65.4893 & 57.26462 \\
\hline October & 22.22958 & 8.59958 & 15.41473 & 47.78124 & 66.229 & 57.005 \\
\hline November & 23.78186 & 8.17648 & 15.97917 & 46.52144 & 66.969 & 56.7417 \\
\hline December & 25.27186 & 7.75288 & 16.51237 & 45.2644 & 67.712 & 56.48672 \\
\hline
\end{tabular}

\section{CONCLUSION}

This paper examined the Markov switching model developed by Hamilton (1989), to capture Markov switching behaviour in the intercept and the variance of Nigeria crude oil prices and inflation rate between January 2006 to December 2019. Eight models were estimated for Markov switching intercept vector autoregressive models to estimate switching between the intercept and the variance of each variable. The AIC and SC test was used, and both tests suggested that MSIH(2)-VAR(2) performed better than the rest models. The appropriate model for the series MSIH (2)-VAR (2). All the process were white noise and invertible. However, the filtered probability provides inference on $s_{t}$ conditional on all available sample information. The fitted model was selected base on minimise information criterion. The best model was also used to forecast the value of the series from January 2020 to December 2020.

\section{REFERENCES}

Benoit, B (2004) MSVARlib: a new Guass library to estimate Multivariate Hidden Markov models. University of Munich, Germany.

Benoit, B (2015). Classical Estimation of Multivariate Markov Switching models Using MSVARlib: Gauss library

Central Bank of Nigeria (2008). Statistical bulletin, 25, Abuja: http://www.cenbank.org

Durka. p and Pastorekov.S (2012) ARIMA Vs ARIMAX which Approach is Better to Analyse and Forecast Macroeconomic Time Series. Proceeding of $30^{\text {th }}$ International Conference Mathematics in Economics.

Gabriele.F, Christophe P and Alessandro.R (2014). Moments give regime in Markov Switching VAR. Retrieved from pdfs.semanticholar.org

Guidolin, M. (2012). Markov Switching Models in Empirical Finance. Advances in Econometrics

Hamilton, J. D. (1989). New Approach to the Economic Analysis of Nonstationary 
Hamilton, J. D. (1990). Analysis of Time series Subject to Changes in Regimes. Journal of Econometrics 45(1), 39-70.

Handoreanu, C.A (2008). The Relationship Between the EUR/RON Exchange Rate and the Romania inflation. European Research Studies 4(1), 71-82

Krolzig H.M and Juan.T (2001) Classical and Modern Business Cycle Measurement: the European case. Department of economic Discussion Pare series. The University of Oxford. : http://www.economics.ox.ac.uk/hendry/krolzig

Krolzig, H.M. (1998). modelling of Markov-switching vector Autoregressive using MSVAR for Ox", Discussion Paper, Department of Economics, University of Oxford: http://www.economics.ox.ac.uk/hendry/krolzig.

Matthieu.D, Ander. W and Tomasz. W (2016). Bayesian Estimation and Inference for Markov Switching VAR in R. Journal of Applied Econometrics. (1-10)

Monbet ,V and Ailliot ,P (2017). Sparse Vector Markov Switching autoregressive Model: Application to Multivariate Time Series of Temperature. Computational Statistics and Data Analysis 8(40-51)

Pls crosscheck the references to accommodate all that is cited in the work?

Quandt .R.E (1972). A New Approach to Estimating Switching Regression. Journal of the American Statistical Association 67,(306-310)

Time Series and the Business Cycle. Journal of Econometrics 57(1), 357-384.

Tong, H. (1990), Nonlinear Time Series Analysis: A Dynamical System Approach New York: Oxford University Press. 